\title{
O ensino de contabilidade de custos nos cursos de graduação em administração do Estado de Santa Catarina
}

Fabiano Maury Raupp

Mestrado em Administração pela Universidade Federal de Santa Catarina - UFSC

Professor da Universidade do Estado de Santa Catarina - UDESC

Av. Madre Benvenuta, 2037, Itacorubi. Florianópolis/SC. CEP: 88035-001

E-mail: fabianoraupp@hotmail.com

Nério Amboni
Doutorado em Engenharia de Produção pela Universidade Federal de Santa Catarina -
UFSC
Professor da Universidade do Estado de Santa Catarina - UDESC
Av. Madre Benvenuta, 2037, Itacorubi. Florianópolis/SC. CEP: 88035-001
E-mail: amboni30@yahoo.com.br

Daniela Regina Cunha

Graduação em andamento em Administração de Empresas pela Universidade do

Estado de Santa Catarina - UDESC

Rua Lauro Linhares, 589, 3o andar, sala 4. Trindade. Florianópolis/SC. CEP: 88036-002

E-mail: daninhacunha@hotmail.com

Juliana Fraga Duarte

Graduação em andamento em Administração de Empresas pela Universidade do

Estado de Santa Catarina - UDESC

Av. Madre Benvenuta, 2037. Itacorubi. Florianópolis/SC. CEP: 88035-001

E-mail: juuduarte@gmail.com

Raquel Crestani Agostineto

Graduação em andamento em Administração de Empresas pela Universidade do

Estado de Santa Catarina - UDESC

Av. Madre Benvenuta, 2037. Itacorubi. Florianópolis/SC. CEP: 88035-001

E-mail:ragostineto@hotmail.com

\section{RESUMO}

O artigo apresenta um estudo sobre o perfil do ensino de Contabilidade de Custos nos cursos de graduação em Administração do Estado de Santa Catarina. Trata-se de um estudo descritivo baseado em uma pesquisa documental, com abordagem qualitativa e quantitativa. Os dados foram coletados por meio de fontes primárias disponibilizadas nos planos de ensino das Instituições de Ensino Superior (IES) e a amostra examinada corresponde a $34,6 \%$ da população. O tópico mais citado nas ementas é terminologia de custos; as aulas expositivas ocupam o primeiro lugar do ranking de metodologias de ensino utilizadas; todas as IES que citam o sistema de avaliação no plano de ensino 
O ensino de contabilidade de custos nos cursos de graduação em administração do Estado de

Santa Catarina

Fabiano Maury Raupp, Nério Amboni, Daniela Regina Cunha, Juliana Fraga Duarte, Raquel Crestani

Agostineto

utilizam a prova como metodologia de verificação de aprendizagem; e o livro Contabilidade de Custos, de Eliseu Martins, é o mais citado nas bibliografias.

Palavras-chave: Ensino. Contabilidade de Custos. Bacharelado em Administração. Santa Catarina.

\section{The teaching of costs accounting to the courses of bachelor degree in business administration within the State of Santa Catarina}

\section{ABSTRACT}

This article presents the teaching profile of costs accounting to the courses of Bachelor Degree in Business Administration within the State of Santa Catarina. This is a descriptive study, done through a documental research, using both qualitative and quantitative approach. The data was collected from primary sources available in the teaching plans, and the obtained sample totalizes $34.6 \%$ of the population. The most mentioned subject in the menu is the terminology of costs; the lecture classes take first place in the ranking of the used teaching methodologies; all the Institution of Teaching that mention the system of teaching plan evaluation apply written tests as the methodology of learning verification; and the book Costs Accounting, by Eliseu Martins, is the most mentioned one.

Key Words: Teaching; Costs Accounting. Course of Bachelor Degree in Business Administration. Santa Catarina.

\section{INTRODUÇÃO}

A Contabilidade vem passando por muitas transformações ao longo de sua história, ao acompanhar as mudanças decorrentes dos novos cenários. Sá (1997) destaca alguns acontecimentos históricos que influenciaram decisivamente a evolução da Contabilidade: o aparecimento das cidades, a estrutura dos Estados, o poder Religioso, o surgimento da moeda, a concentração de riqueza, a divisão do trabalho, o domínio dos mares, a expansão comercial, a Revolução Industrial, a descoberta do papel, a revolução científica, a informática. Todos esses fatores alteraram e continuam alterando a história dessa ciência do patrimônio.

Em um cenário contemporâneo, Franco (1999) expõe que a globalização determina o progresso ou o retrocesso das nações, influindo não somente na economia, mas também na própria cultura dos povos. Vencem o desafio da competição 
O ensino de contabilidade de custos nos cursos de graduação em administração do Estado de Santa Catarina

Fabiano Maury Raupp, Nério Amboni, Daniela Regina Cunha, Juliana Fraga Duarte, Raquel Crestani

Agostineto

internacional aqueles que estão mais preparados para enfrentá-la, isto é, aqueles com melhor formação cultural e técnica.

A informação passa a ser um insumo estratégico às decisões que devem ser tomadas no âmbito das organizações. Isto implica a disponibilização de informações úteis e confiáveis aos gestores sobre os eventos empresariais.

A Contabilidade, por sua vez, com a finalidade de gerar informações que possam satisfazer as necessidades de seus usuários, deve evoluir constantemente para enfrentar este desafio. Conforme Lima e Lopes (1999) há fortes indícios acerca da mudança de percepção dos agentes econômicos sobre o papel da Contabilidade.

Apesar da importância da Contabilidade no gerenciamento das empresas, segundo Tcheou (2002), o ensino de Contabilidade para não contadores tem sido pouco explorado em artigos, seminários e congressos, mesmo sendo a Contabilidade contemplada como disciplina não só nos currículos dos cursos de Administração, como também nos de Direito, Higiene e Saúde, Comunicações, Engenharia e Economia. A inserção acontece também nos cursos de educação continuada, a exemplo dos Master of Business Administration (MBA's) e nos programas de atualização e reciclagem em Contabilidade.

Diante desse contexto, tem-se como objetivo apresentar o perfil do ensino de Contabilidade de Custos nos cursos de graduação em Administração do Estado de Santa Catarina. Aborda-se, inicialmente, a importância da Contabilidade de Custos na gestão empresarial e o ensino de Contabilidade de Custos nos cursos de graduação em Administração. Na seqüência, evidencia-se a metodologia de pesquisa adotada no estudo, destacando os tipos de pesquisa, a população, a amostra, e os instrumentos de coleta e análise dos dados. Em seguida, faz-se a descrição e análise dos dados coletados. Por último, apresentam-se as conclusões da pesquisa realizada.

\section{A IMPORTÂNCIA DA CONTABILIDADE DE CUSTOS NA GESTÃO EMPRESARIAL}

O processo de gestão empresarial requer tomadas de decisão em diferentes áreas da organização como: Administração de Recursos Humanos, Mercado e 
O ensino de contabilidade de custos nos cursos de graduação em administração do Estado de Santa Catarina

Fabiano Maury Raupp, Nério Amboni, Daniela Regina Cunha, Juliana Fraga Duarte, Raquel Crestani Agostineto

Marketing, Materiais, Produção e Logística, Financeira e Orçamentária, Sistemas de Informações, Planejamento Estratégico e Serviços.

No que concerne a áreas específicas como Administração Financeira e Orçamentária e Administração da Produção, há uma intensa relação com o campo de conhecimento das Ciências Contábeis. Para Leone (2002), a Contabilidade e a Administração estiveram sempre relacionadas. A Contabilidade é um instrumento de que dispõe o administrador para o apoio ao cumprimento de suas funções.

É muito importante lembrar que a Contabilidade, embora tenha sido definida, classicamente, como a ciência do patrimônio, apesar da importância desse objeto da Contabilidade, nasceu gerencial, isto é, o dono era também o administrador do negócio. Mas, cada proprietário/gerente podia ter uma idéia diferente sobre o que constar no patrimônio e como avaliar. Mais tarde, com a invenção das partidas dobradas, o custo histórico e uma visão bastante conservadora do que deveria constar no patrimônio acabaram prevalecendo. Digamos que o acompanhamento das variações do patrimônio fornece a base quantitativa e qualitativa de tudo que se segue, em contabilidade (ludícibus, 2007, p.1).

Diante das mudanças do contexto empresarial, que exigiram mudanças nos modelos de gestão de diferentes organizações, a Contabilidade também se modificou. Os avanços no campo gerencial e decisorial foram necessários para ampliar o leque de informações sobre a situação econômico-financeira das organizações.

Paiva (2000) explicita que um sistema de informação contábil estruturado adequadamente pode auxiliar o processo decisório que envolve, principalmente, questões financeiras e econômicas, propiciando informações rápidas, seguras e eficazes, levando as organizações a alcançarem seus objetivos.

Segundo ludícibus (2000, p.35), "os conceitos e metodologias da Contabilidade, associadas ao foco do negócio, garantem sua utilidade como ferramenta para a tomada de decisão". Já Marion e Soares (2001) explicitam que muitos administradores engavetam relatórios, riquíssimos em dados, por não saberem o que fazer com eles, ignorando a sua utilidade e não tomando a melhor decisão. 
O ensino de contabilidade de custos nos cursos de graduação em administração do Estado de Santa Catarina

Fabiano Maury Raupp, Nério Amboni, Daniela Regina Cunha, Juliana Fraga Duarte, Raquel Crestani

Agostineto

Portanto, apesar da utilidade da Contabilidade enquanto instrumento que auxilia o processo decisório, muitos gestores ainda não atentaram para o fato de que os dados e/ou informações contábeis podem influenciar decisões que privilegiam o desenvolvimento ou mesmo sinalizam o retrocesso da empresa. Os demonstrativos elaborados nem sempre são observados, o que faz com que muitos gestores questionem o papel da Contabilidade.

De acordo com Herrmann Jr. (1996), autores dedicados ao estudo de problemas da organização não desconhecem o valor da Contabilidade. Eles consideram o campo contábil como processo prático de demonstração das operações administrativas e dos efeitos que produzem no patrimônio. Reservam à Contabilidade destaque entre os instrumentos que integram a administração científica.

Conforme relatam Groppelli e Nikbakht (2001), os administradores necessitam dos subsídios fornecidos pelos contadores, tais como os demonstrativos financeiros, que informam a lucratividade e a posição financeira de seu empreendimento. Ademais, estas análises fomentam questionamentos, permitindo o controle detalhado do fluxo de caixa da empresa. A partir disso é possível a adoção de políticas que agregam mudanças necessárias ao ambiente interno, criando vantagens na relação externa e, de certa forma, revertendo possíveis impasses.

Particularmente, em relação ao gerenciamento dos custos, o que se tem percebido é que as empresas que estão preocupadas com a competitividade global já não colocam mais a contabilidade de custos como uma função secundária ou terciária. Entre seus objetivos, Matz, Curry e Frank (1974, p.31) destacam:

Visto que trabalha com custos, orçamentos e análise de custo, a Contabilidade de Custos pode ser descrita como sócio principal nas atividades de controle e nas fases de planejamento e de decisões da empresa. A Contabilidade de Custos aplica os princípios contábeis da mesma forma que a Contabilidade Geral e fornece à administração registro detalhado, análise e interpretação das despesas efetuadas em conexão com a operação da empresa.

A Contabilidade de Custos tem se tornado um componente essencial dentro do 
O ensino de contabilidade de custos nos cursos de graduação em administração do Estado de Santa Catarina

Fabiano Maury Raupp, Nério Amboni, Daniela Regina Cunha, Juliana Fraga Duarte, Raquel Crestani Agostineto

processo de gestão da empresa. De acordo com Moscove, Simkin e Bagranoff (2002, p. 28), "contabilidade de custos, orçamento e estudo de sistemas são três componentes de um sistema contábil gerencial de uma companhia".

Koliver (1994) ressalta que a análise de custos oferece um bom campo para reflexões, pois ela já existe há muito tempo e sempre teve por escopo final a redução dos custos das operações, porquanto seu nascimento está ligado à consciência da importância do fator custo na equação do resultado da entidade e, em última instância, à sobrevivência desta num mercado cada vez mais concorrido.

Nesse novo ambiente empresarial são necessárias informações de custos cada vez mais detalhadas e aprimoradas. As empresas estão se dedicando à melhoria de alguns aspectos críticos, tais como: melhor desempenho de produtos e processos, maior sensibilidade para o mercado, melhor gestão estratégica e operacional, entre outras.

Desse modo, onde as informações de custos são usadas para desenvolver estratégias que visam a obtenção da vantagem competitiva pela empresa, gerenciar custos com eficácia exige um enfoque profundo. No entanto, talvez uma exigência maior por parte da Contabilidade de Custos, com ênfase no campo estratégico, tenha se iniciado com a crescente complexidade das indústrias, bem como dos custos industriais.

\section{ENSINO DA CONTABILIDADE DE CUSTOS NOS CURSOS DE GRADUAÇÃO EM ADMINISTRAÇÃO}

As Diretrizes Curriculares Nacionais do Curso de Graduação em Administração, bacharelado, instituídas por meio da Resolução ํo 4, de 13 de julho de 2005, explicitam que as Instituições de Ensino Superior - IES deverão observar na organização curricular que: 
O ensino de contabilidade de custos nos cursos de graduação em administração do Estado de Santa Catarina

Fabiano Maury Raupp, Nério Amboni, Daniela Regina Cunha, Juliana Fraga Duarte, Raquel Crestani

Agostineto

(...)

Art. 5 Os cursos de graduação em Administração deverão contemplar, em seus projetos pedagógicos e em sua organização curricular, conteúdos que revelem inter-relações com a realidade nacional e internacional, segundo uma perspectiva histórica e contextualizada de sua aplicabilidade no âmbito das organizações e do meio através da utilização de tecnologias inovadoras e que atendam aos seguintes campos interligados de formação:

I - Conteúdos de Formação Básica: relacionados com estudos antropológicos, sociológicos, filosóficos, psicológicos, ético-profissionais, políticos, comportamentais, econômicos e contábeis, bem como os relacionados com as tecnologias da comunicação e da informação e das ciências jurídicas;

$(\ldots)$

O texto legal observado cita a Contabilidade como disciplina obrigatória no curso de graduação bacharelado em Administração. A organização das disciplinas é estabelecida de acordo com os critérios definidos em cada Instituição de Ensino Superior.

Segundo Harada (2005), pela própria natureza do curso de Administração de Empresas a carga horária das disciplinas de Contabilidade pode ser insuficiente para repassar todos os fundamentos de Contabilidade. Também o plano de curso da disciplina de Contabilidade pode não ser perfeitamente adequado ao propósito do curso, que seria formar administradores e não contadores.

ludícibus e Marion (2006) sugerem os conteúdos das disciplinas de Contabilidade que devem permear o curso superior de Administração, conforme Quadro 1.

O conteúdo apresentado é definido de acordo com as disciplinas de Contabilidade que são ofertadas no curso de Administração. Com a nomenclatura própria da Contabilidade, normalmente são ofertadas duas disciplinas: Contabilidade Geral e Contabilidade de Custos.

Para Vasconcelos (2000), convém ressaltar que, em geral, o que se ensina a todos os estudantes, independentemente de sua área de formação, é o mesmo conteúdo programático que se ministra aos estudantes de Ciências Contábeis, com a 
O ensino de contabilidade de custos nos cursos de graduação em administração do Estado de Santa Catarina

Fabiano Maury Raupp, Nério Amboni, Daniela Regina Cunha, Juliana Fraga Duarte, Raquel Crestani Agostineto

agravante de que os estudantes de outros cursos geralmente só têm contato com a disciplina Contabilidade Geral, e esta é ensinada com a visão tradicional, ou seja, de registro das operações. Tcheou (2002, p.25) aduz que

deve-se ensinar aos administradores a Contabilidade como ciência e como arte. A primeira, por estudar a representação do patrimônio das organizações; a segunda, por apresentar um conjunto de regras e prescrições, considerando uma importante fonte de informações de dados fiéis e reais que subsidiam e apóiam a decisão do administrador.

\begin{tabular}{|c|c|}
\hline Curso & Conteúdo \\
\hline $\begin{array}{c}\text { Administração de Empresas } \\
\text { (Contempla as disciplinas de Custos e } \\
\text { Análise de Balanços) }\end{array}$ & $\begin{array}{l}\text { 1. Relatórios Contábeis } \\
\text { 2. Introdução - Balanço Patrimonial } \\
\text { 3. Balanço Patrimonial - Grupo de Contas } \\
\text { 4. Tomar decisões } \\
\text { 5. Demonstrativo do Resultado do Exercício } \\
\text { 6. Demonstração de Lucros ou Prejuízos Acumulados } \\
\text { 7. Demonstração das Origens e Aplicações de } \\
\text { Recursos } \\
\text { 8. Análise I } \\
\text { 9. Análise II } \\
\text { 10. Custos } \\
\text { 11. Cálculo de Custos } \\
\text { 12. Custos para Decisão } \\
\text { 13. Custos para Controle } \\
\text { 14. Processo Contábil }\end{array}$ \\
\hline $\begin{array}{c}\text { Administração de Empresas } \\
\text { (Não contempla as disciplinas de } \\
\text { Contabilidade de Custos e Análise de } \\
\text { Balanços) }\end{array}$ & $\begin{array}{l}\text { 1. Relatórios Contábeis } \\
\text { 2. Introdução - Balanço Patrimonial } \\
\text { 3. Balanço Patrimonial - Grupo de Contas } \\
\text { 4. Tomar decisões } \\
\text { 5. Demonstrativo do Resultado do Exercício } \\
\text { 6. Demonstração de Lucros ou Prejuízos Acumulados } \\
\text { 7. Demonstração das Origens e Aplicações de } \\
\text { 8. Procesursos } \\
\text { 8. Processo Contábil }\end{array}$ \\
\hline
\end{tabular}

Quadro 1: Sugestão de conteúdo das disciplinas de Contabilidade para o curso superior de Administração

Fonte: ludícibus e Marion (2006)

De acordo com Oliveira (2003), o ensino de Contabilidade deve ter como propósito a tomada de decisão considerando os recursos escassos, incluindo a identificação de decisões cruciais das áreas e a determinação de objetivos e metas; fornecer subsídios à direção e controle efetivo de recursos e materiais; prover relatórios 
O ensino de contabilidade de custos nos cursos de graduação em administração do Estado de Santa Catarina

Fabiano Maury Raupp, Nério Amboni, Daniela Regina Cunha, Juliana Fraga Duarte, Raquel Crestani Agostineto

gerenciais sobre custo dos recursos com identificação dos pontos críticos e oportunidades de melhorias; além de facilitar o controle e a função social.

Segundo Marion (2007), deve-se ensinar o não contador a entender e a interpretar a Contabilidade sem desconsiderar a importância de demonstrar o como fazer. A questão é a ênfase em como fazer a Contabilidade.

Apesar do destaque que os conhecimentos contábeis alcançaram no campo da Administração, a bibliografia para o curso ainda é muito restrita. ludícibus e Marion (2006) constatam a escassez de materiais que abordam a real necessidade da Contabilidade para os administradores. A ênfase principal (interpretação dos Relatórios Contábeis) é simplesmente desprezada. Entendem que o ensino da Contabilidade para não contadores deveria ser voltado para os Relatórios Contábeis e sua interpretação.

Cabe aos gestores dos cursos de graduação em Administração direcionar os conhecimentos das Ciências Contábeis para as necessidades impostas à carreira profissional do administrador. O graduando não necessita de teorias e estudos complexos em Contabilidade, mas de foco naquilo que é primordial para o desenvolvimento da sua carreira.

\section{PROCEDIMENTOS METODOLÓGICOS ADOTADOS}

Os delineamentos possuem um importante papel na pesquisa científica. No tocante à tipologia relacionada aos objetivos, esta pesquisa consiste de um estudo do tipo descritivo. A pesquisa descritiva preocupa-se em observar os fatos, registrá-los, analisá-los, classificá-los e interpretá-los, sendo que o pesquisador não interfere sobre eles. Os fenômenos do mundo físico e humano são estudados, mas não são manipulados pelo pesquisador (ANDRADE, 2002).

No que concerne aos procedimentos técnicos a pesquisa é do tipo documental, e quanto à abordagem do problema o estudo utilizou-se da abordagem quali-quantitativa. O foco das Ciências Sociais está no estudo qualitativo, na medida em que caminha para o universo de significações. Entende-se a metodologia de pesquisa qualitativa como capaz de incorporar questões e intencionalidades inerentes aos atos, relações e 
O ensino de contabilidade de custos nos cursos de graduação em administração do Estado de Santa Catarina

Fabiano Maury Raupp, Nério Amboni, Daniela Regina Cunha, Juliana Fraga Duarte, Raquel Crestani Agostineto

às estruturas sociais (MINAYO, 1998).

O método qualitativo diferencia-se do quantitativo na medida em que não emprega instrumentos estatísticos como base no processo de análise de um problema, não há intenção de numerar ou medir unidades ou categorias homogêneas. Já a abordagem quantitativa caracteriza-se pelo emprego de técnicas estatísticas, desde as mais simples como percentual, média, desvio-padrão, às mais complexas, como coeficientes de correlação, análise de regressão, etc (RICHARDSON, 1999).

A perspectiva do estudo é de corte transversal ou seccional, pois os dados foram coletados em um determinado ponto no tempo, tendo por base uma amostra para descrever as características da população num momento definido. No corte transversal, identifica-se a população, escolhe-se a amostra e realiza-se a pesquisa (RICHARDSON, 1999).

O objeto de análise do estudo é organizacional, contemplando uma população de 81 IES com o curso de graduação bacharelado em Administração no Estado de Santa Catarina. Para tal, consultou-se uma relação disponibilizada pelo Conselho Regional de Administração de Santa Catarina - CRASC, no site do referido conselho (http://www.crasc.org.br).

Em virtude da impossibilidade de analisar todas as IES, optou-se por estudar uma amostra. O método escolhido é do tipo não-probabilístico. A amostragem nãoprobabilística ocorre quando há uma escolha deliberada dos elementos da amostra (MARTINS, 2000).

Em meio aos tipos de amostragens não-probabilísticas, optou-se pela amostragem por acessibilidade ou conveniência. Na amostragem por acessibilidade o pesquisador obtém os elementos a que tem maior facilidade de acesso, admitindo que eles possam efetivamente representar de forma adequada a população (GIL, 1999).

Considerou-se como amostra as IES que disponibilizaram os planos de ensino das disciplinas de Contabilidade de Custos. Obteve-se o retorno de 28 IES, correspondendo a $34,60 \%$ da população. Na Tabela 1 apresenta-se a relação das IES participantes da pesquisa.

Quanto à categoria de análise, refere-se aos planos de ensino de Contabilidade 
O ensino de contabilidade de custos nos cursos de graduação em administração do Estado de Santa Catarina

Fabiano Maury Raupp, Nério Amboni, Daniela Regina Cunha, Juliana Fraga Duarte, Raquel Crestani Agostineto

de Custos. Os dados foram coletados por meio de fontes primárias disponibilizadas nos planos de ensino. Os planos de ensino foram solicitados, primeiramente, através de email encaminhado aos coordenadores dos cursos de graduação em Administração, cujos endereços foram extraídos da relação disponibilizada pelo CRASC. Porém, constatou-se que os endereços eletrônicos de alguns coordenadores haviam mudado, bem como alguns coordenadores informados na relação disponibilizada pelo CRASC não ocupavam mais tal função.

Em uma segunda etapa resolveu-se contatá-los por telefone, cujo número também fazia parte da relação disponibilizada pelo CRASC. Outros planos de ensino foram obtidos no site de algumas IES.

A análise dos dados coletados na pesquisa deu-se por meio das técnicas de análise de conteúdo e análise descritiva. $A$ análise de conteúdo refere-se a um conjunto de técnicas de análise das comunicações visando obter, por meio de procedimentos sistemáticos e objetivos de descrição de conteúdo das mensagens, indicadores que permitam inferir conhecimentos relativos às condições de produção dessas mensagens (BARDIN, 1979 apud RICHARDSON, 1999). 
O ensino de contabilidade de custos nos cursos de graduação em administração do Estado de Santa Catarina

Fabiano Maury Raupp, Nério Amboni, Daniela Regina Cunha, Juliana Fraga Duarte, Raquel Crestani Agostineto

Tabela 1: IES de SC com curso de graduação em Administração participantes da pesquisa

\begin{tabular}{|c|c|}
\hline N.o & Relação das IES Participantes da Pesquisa \\
\hline 01 & Centro de Educação Superior - UNICA \\
\hline 02 & Centro Universitário de Brusque - UNIFEBE \\
\hline 03 & Complexo de Ensino Superior de Santa Catarina - CESUSC \\
\hline 04 & Escola Superior de Criciúma - ESUCRI \\
\hline 05 & Faculdade Avantis \\
\hline 06 & Faculdade Capivari - FUCAP \\
\hline 07 & Faculdade Cenecista de Joinville - FCJ \\
\hline 08 & Faculdade Concórdia - FACC \\
\hline 09 & Faculdade de Itapiranga - FAI \\
\hline 10 & Faculdade Decisão \\
\hline 11 & Faculdade Exponencial - FIE \\
\hline 12 & Faculdades Energia de Administração e Negócios - FEAN \\
\hline 13 & Faculdades Integradas da Rede de Ensino UNIVEST - FACVEST \\
\hline 14 & Fundação Universidade do Contestado - UNC (Campus de Curitibanos) \\
\hline 15 & Instituto de Ensino Superior Santo Antônio - INESA \\
\hline 16 & Instituto do Saber de Ensino Superior - ISES \\
\hline 17 & Instituto Superior Tupy - IST \\
\hline 18 & Universidade Comunitária Regional de Chapecó - UNOCHAPECÓ (Campus de Chapecó) \\
\hline 19 & Universidade da Região de Joinville - UNIVILLE (Campus de Joinville) \\
\hline 20 & Universidade do Estado de Santa Catarina - UDESC \\
\hline 21 & Universidade do Extremo Sul Catarinense - UNESC \\
\hline 22 & Universidade do Oeste de Santa Catarina - UNOESC (Campus de São Miguel D’Oeste) \\
\hline 23 & Universidade do Planalto Catarinense - UNIPLAC (Campus de Lages) \\
\hline 24 & Universidade do Planalto Catarinense - UNIPLAC (Campus de Urubici) \\
\hline 25 & Universidade do Sul de Santa Catarina - UNISUL (Campus de Araranguá) \\
\hline 26 & Universidade do Sul de Santa Catarina - UNISUL (Campus do Norte da Ilha) \\
\hline 27 & Universidade do Vale do Itajaí - UNIVALI (Campus de Balneário Camboriú) \\
\hline 28 & Universidade Federal de Santa Catarina - UFSC \\
\hline
\end{tabular}

Fonte: Dados da pesquisa, 2008

A análise descritiva é utilizada para relatar o comportamento de uma variável em uma população ou no interior de uma subpopulação, utilizando para a análise dos dados os instrumentos disponibilizados pela estatística (Contandriopoulos et al., 1994). As técnicas de análise de dados abordadas são amplamente empregadas nas Ciências Sociais em virtude de diversos trabalhos nesta área demandarem uma abordagem quali-quantitativa.

\section{DESCRIÇÃO E ANÁLISE DOS RESULTADOS}

Nesta seção apresentam-se os resultados da pesquisa realizada. Inicia-se com a apresentação das denominações utilizadas em disciplinas de Contabilidade de Custos 
O ensino de contabilidade de custos nos cursos de graduação em administração do Estado de Santa Catarina

Fabiano Maury Raupp, Nério Amboni, Daniela Regina Cunha, Juliana Fraga Duarte, Raquel Crestani Agostineto

nos cursos de graduação em Administração. Em seguida, identificam-se os tópicos contemplados na ementa e no conteúdo programático. Por fim, verificam-se as metodologias de ensino, o sistema de avaliação e as bibliografias citadas nos planos de ensino.

\subsection{Denominações em disciplinas de contabilidade de custos}

A disciplina Contabilidade de Custos geralmente faz parte da grade do terceiro semestre. Das 28 IES que compuseram a amostra da pesquisa, todas contemplam na grade curricular do curso de graduação em Administração, no mínimo, uma disciplina que trabalha com os conteúdos da Contabilidade de Custos. Na Tabela 2 apresentamse as denominações que as IES de SC dão à disciplina que oferta o conteúdo de Contabilidade de Custos.

Tabela 2: Denominações da disciplina que oferece o conteúdo da Contabilidade de Custos

\begin{tabular}{|c|c|}
\hline Denominacão & Ocorrência \\
\hline Administracão de Custos & 4 \\
\hline Custos Empresariais & 4 \\
\hline Gestão de Custos & 4 \\
\hline Contabilidade Gerencial & 3 \\
\hline Custos & 3 \\
\hline Contabilidade de Custos & 2 \\
\hline Custos Gerenciais & 2 \\
\hline Teoria de Custos & 2 \\
\hline Análise de Controle de Custos & 2 \\
\hline Custos e Controladoria & 1 \\
\hline Gestão de Custos e Formacão de Precos & 1 \\
\hline Total & 28 \\
\hline
\end{tabular}

Fonte: Dados da pesquisa (2008)

As denominações mais utilizadas são Administração de Custos, Custos Empresarias e Gestão de Custos, todas com 4 ocorrências. Com ocorrência 3 foram apontadas Contabilidade Gerencial e Custos. 
O ensino de contabilidade de custos nos cursos de graduação em administração do Estado de Santa Catarina

Fabiano Maury Raupp, Nério Amboni, Daniela Regina Cunha, Juliana Fraga Duarte, Raquel Crestani

Agostineto

\subsection{Tópicos contemplados na ementa das disciplinas}

A ementa é considerada um dos elementos norteadores do plano de ensino, bem como do desenvolvimento do processo ensino-aprendizagem da disciplina. Para inferir sobre o ensino de Contabilidade de Custos, analisou-se os tópicos dos ementários, considerando aqueles com uma ocorrência igual ou superior a 5 . Os tópicos mais citados nas ementas são identificados na Tabela 3.

Tabela 3: Tópicos citados nas ementas de Contabilidade de Custos

\begin{tabular}{|c|c|}
\hline Tópicos do Ementário & Ocorrência \\
\hline Terminologia de custos & 16 \\
\hline Formacão de preços & 15 \\
\hline Relacão custo/volume/lucro & 14 \\
\hline Métodos de custeio & 13 \\
\hline Classificação de custos & 12 \\
\hline Custos para controle & 11 \\
\hline Custos para tomada de decisões & 11 \\
\hline Custeio variável & 8 \\
\hline Custeio por absorção & 7 \\
\hline Análise de custos & 6 \\
\hline Custo padrão & 6 \\
\hline Custos para planeiamento & 6 \\
\hline Centro de custos & 6 \\
\hline Custeio baseado em atividades & 5 \\
\hline Departamentalização & 5 \\
\hline Mão-de-obra direta & 5 \\
\hline Materiais diretos & 5 \\
\hline Orçamento & 5 \\
\hline Relação contabilidade financeiracão & 5 \\
\hline contabilidade de custos/contabilidade gerencial & 5 \\
\hline
\end{tabular}

Fonte: Dados da pesquisa (2008)

O tópico mais citado foi terminologia de custos, com 16 ocorrências. $\mathrm{Na}$ seqüência aparece formação de preços e relação custo/volume/lucro, com 15 e 14 ocorrências, respectivamente. Os tópicos citados nos ementários corroboram com a proposta de ludícibus e Marion (2006) quando sugerem os conteúdos das disciplinas de Contabilidade que devem permear o curso superior de Administração.

\subsection{Tópicos contemplados no conteúdo programático das disciplinas}

O conteúdo programático representa o desdobramento da ementa da disciplina. 
O ensino de contabilidade de custos nos cursos de graduação em administração do Estado de Santa Catarina

Fabiano Maury Raupp, Nério Amboni, Daniela Regina Cunha, Juliana Fraga Duarte, Raquel Crestani Agostineto

A preocupação na escolha dos tópicos que deverão constar no conteúdo programático do plano de ensino deve-se a necessidade de desenvolver a ementa durante o período letivo.

A tabulação acerca do conteúdo programático das disciplinas de Contabilidade de Custos considerou tópicos com ocorrência igual ou superior a 5 . Na Tabela 4 apresentam-se os tópicos citados nos planos de ensino.

Tabela 4: Tópicos contemplados nos conteúdos programáticos de Contabilidade de Custos

\begin{tabular}{|c|c|}
\hline Conteúdos Programáticos & Ocorrência \\
\hline Relação custo/volume/lucro & 20 \\
\hline Custeio variável & 19 \\
\hline Ponto de equilíbrio & 19 \\
\hline Margem de contribuição & 17 \\
\hline Classificação dos custos e despesas de acordo com sua natureza & 16 \\
\hline Custeio $A B C$ & 16 \\
\hline Métodos de custeio & 16 \\
\hline Custeio por absorção & 15 \\
\hline Conceitos/definições fundamentais /básicas de custos & 14 \\
\hline Formação do preço de venda & 14 \\
\hline Terminologia aplicável na contabilidade de custos & 11 \\
\hline Centro de custos & 10 \\
\hline Custos fixos & 8 \\
\hline Margem de segurança & 8 \\
\hline Alavancagem operacional & 7 \\
\hline Custeio padrão & 7 \\
\hline Mark-up & 7 \\
\hline Avaliação de estoques & 6 \\
\hline Custos indiretos & 6 \\
\hline Departamentalização & 6 \\
\hline Objetivos de custos & 6 \\
\hline Análise das variações entre custo real e custo padrão & 5 \\
\hline Co-produtos, subprodutos e sucatas & 5 \\
\hline Custo da mão-de-obra & 5 \\
\hline Custos & 5 \\
\hline Custos variáveis & 5 \\
\hline Despesa & 5 \\
\hline Esquema básico da contabilidade de custos & 5 \\
\hline Gasto & 5 \\
\hline Investimento & 5 \\
\hline Mão-de-obra direta & 5 \\
\hline Método unidade esforço de produção (UEP) & 5 \\
\hline PEPS ou FIFO & 5 \\
\hline UEPS ou LIFO & 5 \\
\hline
\end{tabular}

Fonte: Dados da pesquisa (2008)

Nota-se que a relação custo-volume-lucro é o item mais citado, com 20 
O ensino de contabilidade de custos nos cursos de graduação em administração do Estado de Santa Catarina

Fabiano Maury Raupp, Nério Amboni, Daniela Regina Cunha, Juliana Fraga Duarte, Raquel Crestani Agostineto

ocorrências. Em seguida, e com igual ocorrência (19) cita-se o custeio variável e o ponto de equilíbrio. A margem de contribuição ocupa a terceira colocação, com 17 ocorrências. Alguns dos conteúdos que possuem uma ocorrência igual a 5 correspondem aos conceitos fundamentais no ensino da Contabilidade de Custos, como os conceitos de gasto, custos, despesa e investimento.

\subsection{Metodologias de ensino utilizadas}

Seguindo-se com os tópicos abordados nos planos de ensino de Contabilidade de Custos, a tabulação de dados também investigou as metodologias de ensino utilizadas durante o processo de ensino-aprendizagem, considerando aquelas com ocorrência igual ou superior a 5 . As metodologias de ensino mais utilizadas na disciplina Contabilidade de Custos são apresentadas na Tabela 5.

Tabela 5: Metodologias de ensino utilizadas na disciplina de Contabilidade de Custos

\begin{tabular}{|c|c|}
\hline Metodologia & Ocorrência \\
\hline Aulas expositivas & 22 \\
\hline Exercícios & 18 \\
\hline Estudos de caso & 11 \\
\hline Trabalhos em equipe & 5 \\
\hline
\end{tabular}

Fonte: Dados da pesquisa (2008)

As aulas expositivas correspondem à metodologia mais utilizada dentre as instituições, com 22 ocorrências. Os exercícios ocupam o segundo lugar com 18 ocorrências. Os estudos de caso apresentaram 11 ocorrências nas IES analisadas. Por fim, com 5 ocorrências, encontram-se os trabalhos realizados em equipe. Os seminários/apresentações, trabalhos individuais e os debates/discussão em sala de aula não ocupam posição de destaque.

\subsection{Sistema de avaliação citado nos planos de ensino}

$\mathrm{Na}$ análise dos elementos que estruturam o ensino de Contabilidade de Custos nos cursos de graduação em Administração de SC, identificou-se o sistema de avaliação citado nos planos de ensino. Dentre os 28 planos de ensino de Contabilidade 
O ensino de contabilidade de custos nos cursos de graduação em administração do Estado de Santa Catarina

Fabiano Maury Raupp, Nério Amboni, Daniela Regina Cunha, Juliana Fraga Duarte, Raquel Crestani Agostineto

de Custos que compuseram a amostra, 22 citavam o sistema de avaliação utilizado. $\mathrm{Na}$ Tabela 6 são apresentadas as tipologias de avaliação citadas nos planos de ensino, consideradas aquelas com ocorrência igual ou superior a 5.

Tabela 6: Sistema de avaliação da disciplina Contabilidade de Custos

\begin{tabular}{|c|c|}
\hline Sistema de Avaliação & Ocorrência \\
\hline Provas & 28 \\
\hline Trabalhos & 18 \\
\hline Exercícios & 10 \\
\hline Participação & 9 \\
\hline
\end{tabular}

Fonte: Dados primários (2008)

Nota-se que a prova é o único método presente em todos os planos que citam o sistema de avaliação, com 28 ocorrências, seguido pelos trabalhos e exercícios, com 18 e 10 ocorrências, respectivamente. Dentre uma ocorrência igual ou superior a 5 a tipologia menos citada é a participação.

Das 28 IES analisadas, 11 citam a quantidade de provas utilizada, ou seja, 5 IES utilizam 2 provas, 5 IES utilizam 3 provas e 1 IES utiliza 4 provas. Quanto aos trabalhos, a quantidade que prepondera é de um trabalho por semestre, considerando que apenas 9 planos de ensino citam esta quantidade. Para os outros tipos de avaliação não foi possível identificar a quantidade, visto que os planos de ensino analisados não a divulgam.

\subsection{Bibliografias citadas nos planos de ensino}

$\mathrm{Na}$ análise das bibliografias citadas nos planos de ensino, fez-se a compilação dos autores e suas respectivas obras, possibilitando visualizar as mais recorrentes. Optou-se pela tabulação daquelas que ocorriam em uma freqüência igual ou superior a 5. Os livros mais citados nos planos de ensino de Contabilidade de Custos são apresentados na Tabela 7.

$\mathrm{Na}$ Tabela 7 percebe-se uma discrepância proeminente no que se refere ao ranking de ocorrências. O livro mais citado é Contabilidade de Custos, de Eliseu Martins, com 22 ocorrências, seguido da obra Análise Gerencial de Custos: aplicação 
O ensino de contabilidade de custos nos cursos de graduação em administração do Estado de Santa Catarina

Fabiano Maury Raupp, Nério Amboni, Daniela Regina Cunha, Juliana Fraga Duarte, Raquel Crestani Agostineto

em empresas modernas, de Antônio Cezar Bornia, indicado por 8 IES. Considerando uma ocorrência igual ou superior a 5, os livros menos citados foram: Curso Básico de Contabilidade de Custos, de Silvio Aparecido Crepaldi, e Gestão Estratégica de Custos, de José H. Perez Júnior; Luiz M. Oliveira e Rogério Costa, ambos com 5 ocorrências.

Tabela 7: Livros citados nos planos de ensino que abordam a contabilidade de custos

\begin{tabular}{|c|c|}
\hline Obra & Ocorrência \\
\hline MARTINS, Eliseu. Contabilidade de custos. São Paulo: Atlas, 2003. & 22 \\
\hline $\begin{array}{c}\text { modernas. Porto Alegre: Bookman, 2002. } \\
\text { moRNIA, Antonio emar. empresas }\end{array}$ & 8 \\
\hline $\begin{array}{c}\text { HORNGREN, Charles Thomas; FOSTER, George; DATAR, Srikant. Contabilidade de } \\
\text { custos: um enfoque administrativo. Rio de Janeiro: LTC, 2000. }\end{array}$ & 7 \\
\hline IUDÍCIBUS, Sérgio de. Contabilidade gerencial. São Paulo: Atlas, 2005. & 7 \\
\hline $\begin{array}{c}\text { MAHER, Michael. Contabilidade de custos: criando valor para a administração. São } \\
\text { Paulo: Atlas, 2001. }\end{array}$ & 7 \\
\hline $\begin{array}{c}\text { ARUNI, Adriano Leal; FAMÁ, Rubens. Gestão de custos e formação de preços: com } \\
\text { aplicações na calculadora financeira HP-12C e Excel. São Paulo: Atlas, 2004. }\end{array}$ & 6 \\
\hline $\begin{array}{c}\text { LEONE, George Sebastião Guerra. Custos: planejamento, implantação e controle. São } \\
\text { Paulo: Atlas, 2000. }\end{array}$ & 6 \\
\hline $\begin{array}{c}\text { LEONE, George Sebastião Guerra. Curso de contabilidade de custos: contém critério } \\
\text { do custeio ABC. São Paulo: Atlas, 2000. }\end{array}$ & 6 \\
\hline $\begin{array}{c}\text { LEONE, George Sebastião Guerra. Custos: um enfoque administrativo. Rio de Janeiro: } \\
\text { FGV, 2002. }\end{array}$ & 6 \\
\hline $\begin{array}{c}\text { Atlas, 2002. } \\
\text { CREPALDI, Silvio Aparecido. Curso básico de contabilidade de custos. São Paulo: }\end{array}$ & 5 \\
\hline $\begin{array}{c}\text { PEREZ JR., José H.; OLIVEIRA, Luiz M.; COSTA, Rogério. G. Gestão estratégica de } \\
\text { custos. São Paulo: Atlas, 2001. }\end{array}$ & 5 \\
\hline
\end{tabular}

Fonte: Dados da pesquisa (2008)

\section{CONCLUSÃO}

O presente estudo objetivou apresentar o perfil do ensino de Contabilidade de Custos nos cursos de graduação em Administração do Estado de Santa. As denominações mais utilizadas para os conteúdos de custos são Administração de Custos, Custos Empresarias e Gestão de Custos, todas com 4 ocorrências.

Os tópicos mais citados nas ementas de Contabilidade de Custos foram: terminologia de custos, com 16 ocorrências, e formação de preços e relação custo/volume/lucro, com 15 e 14 ocorrências, respectivamente. 
O ensino de contabilidade de custos nos cursos de graduação em administração do Estado de Santa Catarina

Fabiano Maury Raupp, Nério Amboni, Daniela Regina Cunha, Juliana Fraga Duarte, Raquel Crestani

Agostineto

No tocante aos conteúdos programáticos de Contabilidade de Custos, observase que a relação custo-volume-lucro é o item mais citado, com 20 ocorrências. Com igual ocorrência, 19, cita-se o custeio variável e o ponto de equilíbrio. A margem de contribuição ocupa a terceira colocação com 17 ocorrências.

As aulas expositivas ocupam o primeiro lugar do ranking de metodologias de ensino utilizadas na Contabilidade de Custos, com 22 ocorrências. Os exercícios ocupam o segundo lugar com 18 ocorrências e os estudos de caso apresentaram 11 ocorrências nas IES analisadas.

A prova está presente em todos os planos que citam o sistema de avaliação, com 28 ocorrências, seguido pelos trabalhos e exercícios, com 18 e 10 ocorrências, respectivamente.

Dentre os livros mais citados há uma discrepância no que se refere ao ranking de ocorrências. O livro mais citado é Contabilidade de Custos, de Eliseu Martins, com 22 ocorrências, seguido da obra Análise Gerencial de Custos: aplicação em empresas modernas, de Antônio Cezar Bornia, adotado por 8 IES.

\section{REFERÊNCIAS}

ANDRADE, Maria Margarida. (2002). Como preparar trabalhos para cursos de pósgraduação: noções práticas. (5 ed.). São Paulo: Atlas.

BRASIL. CONSELHO NACIONAL DE EDUCAÇÃO/CÂMARA DE EDUCAÇÃO SUPERIOR. Resolução no 4, de 13 de julho de 2005. Institui as Diretrizes Curriculares Nacionais do curso de Graduação em Administração, bacharelado, e dá outras providências. Diário Oficial da União, Brasília, 19 de julho de 2005, Seção 1, p. 26 e 27.

CONSELHO REGIONAL DE ADMINISTRAÇÃO DE SANTA CATARINA. Universidades/faculdades de administração de Santa Catarina. Disponível em: $<$ www.crasc.org.br>. Acesso em: 20/jul/2007.

CONTANDRIOPOULOS, André-Pierre et al. (1994). Saber preparar uma pesquisa: definição estrutura e financiamento. São Paulo: Hucitec Abrasco.

FRANCO, Hilário. (1999). Contabilidade na era da globalização. São Paulo: Atlas.

GIL, A. C. (1999). Métodos e técnicas de pesquisa social. São Paulo: Atlas. 
O ensino de contabilidade de custos nos cursos de graduação em administração do Estado de

Santa Catarina

Fabiano Maury Raupp, Nério Amboni, Daniela Regina Cunha, Juliana Fraga Duarte, Raquel Crestani

Agostineto

GROPPELLI, A.A.; NIKBAKHT, Ehsan. (2001). Administração financeira. São Paulo. Saraiva.

HARADA, Ronaldo Setsuo. (2005). O ensino de contabilidade no curso de administração de empresas: a percepção dos docentes da disciplina de contabilidade geral em faculdades localizadas no município de São Paulo. 109f. (Dissertação de Mestrado). Programa de Mestrado em Ciências Contábeis, Fundação Escola de Comércio Álvares Penteado, São Paulo.

HERRMANN JÚNIOR, Frederico. (1996). Contabilidade superior. São Paulo: Atlas.

IUDICÍBUS, Sérgio de. (2000). Teoria da contabilidade. São Paulo: Atlas.

IUDíCIBUS, Sérgio de. (2007). Contabilidade: entre umas e outras. Revista de Informação Contábil. Recife, v. 1, n. 1, p. 1-6, set.

IUDÍCIBUS, Sérgio de; MARION, José Carlos. (2006). Curso de contabilidade para não contadores. São Paulo: Atlas.

KOLIVER, O. (1994). A contabilidade de custos: algo de novo sob o sol? In: Seminário Interamericano de Contabilidade. Brasília: Conselho Federal de Contabilidade.

LEONE, George Sebastião Guerra. (2002). Custos: um enfoque administrativo. Rio de Janeiro: FGV.

LIMA, Iran Siqueira; LOPES, Alexsandro Broedel. (1999). Contabilidade e controle de operações com derivativos. São Paulo: Pioneira.

MARION, José Carlos. (2007). Contabilidade empresarial. São Paulo: Atlas.

MARION, José Carlos; SOARES, Adenilson Honório. (2000). Contabilidade como instrumento para tomada de decisões. Campinas: Alínea.

MARTINS, Gilberto de Andrade. (2000). Manual para elaboração de monografias e dissertações. São Paulo: Atlas.

MATZ, A.: CURRY, O.J.; FRANK, G.W. (1974). Contabilidade de custos. São Paulo: Atlas.

MINAYO, Maria Cecília de Souza. (1998). Ciência, técnica e arte: o desafio da pesquisa social. In: MINAYO, Maria Cecília de Souza (Org.). Pesquisa social: teoria, método e criatividade. Petrópolis: Vozes. 
O ensino de contabilidade de custos nos cursos de graduação em administração do Estado de Santa Catarina

Fabiano Maury Raupp, Nério Amboni, Daniela Regina Cunha, Juliana Fraga Duarte, Raquel Crestani

Agostineto

MOSCOVE, S. A.; SIMKIN, Mark G.; BAGRANOFF, Nancy A. (2002). Sistemas de informações contábeis. São Paulo: Atlas.

OLIVEIRA, Edson. (2003). Contabilidade informatizada. São Paulo: Atlas.

PAIVA, Simone Bastos. (2000). O processo decisório e a informação contábil: entre objetividades e subjetividades. Revista Brasileira de Contabilidade, Brasília, n. 123, p. 76-83, maio/jun.

RAUPP, Fabiano Maury; BEUREN, Ilse Maria. (2003). Metodologia da pesquisa aplicável nas Ciências Sociais. In: BEUREN, Ilse Maria (Org.). Como elaborar trabalhos monográficos em contabilidade: teoria e prática. São Paulo: Atlas.

RICHARDSON, Roberto Jarry. (1999). Pesquisa social: métodos e técnicas. São Paulo: Atlas.

SÁ, Antônio Lopes de. (1997). História geral e das doutrinas da contabilidade. São Paulo: Atlas.

TCHEOU, Ellen. (2002). Avaliação do ensino de contabilidade nos cursos de administração de empresas na cidade de São Paulo. 203f. (Dissertação de Mestrado). Programa de Mestrado em Ciências Contábeis, Fundação Escola de Comércio Álvares Penteado, São Paulo.

VASCONCELOS, Nanci Pereira de. (2000). Uma contribuição para a melhoria da qualidade do ensino em Ciências Contábeis - uma abordagem sistêmica. Revista Brasileira de Contabilidade, Brasília, n. 125, p. 30-36, set./out.

Data de Submissão: 30/12/2008

Data de Aceite: 19/06/2009 